\title{
BIBLIOGRAFIE VAN DE GESCHIEDENIS VAN GENT 1989-1990*
}

\author{
door \\ René DE HERDT en Johan VANNIEUWENHUYSE \\ MIAT en Stadsarchief Gent
}

Inventarissen, bibliografieën

1. BUNTINX W., Bedrijfsarchief in een familiearchief. Het familiearchief Vilain XIIII. Een overzicht, in Actief in archief. Huldeboek Hilda Coppejans-Desmedt, (Vlaamse Vereniging voor Bibliotheek-, Archief-en Documentatierwezen. Archiefkunde, 4), Antwerpen, 1989, p. 63-73.

Het familiearchief Vilain XIIII, bewaard op het Rijksarchief te Gent, bevat onder meer koopliedenarchieven van de familie de Richebourcq (Gent-Antwerpen, 17de-18de eeuw) en van de stoffenhandelaar Jan Toebast (Gent, 17de eeuw), alsook bescheiden van transportondernemingen : de stoombootmaatschappij Mercurius (Antwerpen-Gent, 19de eeuw) en de spoorwegmaatschappij Antwerpen-Gent (19de eeuw).

2. BUNTINX W., Het archief van het soeverein-baljureschap van Vlaanderen in het Rijksarchief te Gent, in Liber Amicorum Achiel De Vos, Evergem, 1989, p. 67-70.

3. CARLIER M. en A. DEPREZ, De Vlinder 1867. De Biekorf 1867. Ieders Belang 1868. Meiloover 1868-1870. Het Vlaamsche Volk 1870-1872. Jaarboekje van Zetternamskring 1873-1875. Jaarboek der Letterkundige Vereeniging Jan Frans Willems 1867-1890, (Rijksuniversiteit. Cultureel Documentatiecentrum. Bibliografie van de Vlaamse Tijdschriften in de Negentiende Eeuw), Gent, 1989, $254 \mathrm{blz}$.

Ontleding van onder meer de Gentse Vlaamsgezinde tijdschriften Meiloover, Het Vlaamsche Volk en Jaarboekje van Zetternamskring. Met inleiding, auteurs- en trefwoordenregisters.

4. CARLIER M. en A. DEPREZ, Jong Vlaanderen 1889-1890. Ons Tooneel 1890-1891. De Eikel 1889. De Vrije Vlucht 1890. Onze Kunst

\footnotetext{
* Gebruikte afkorting: HMGOG = Handelingen der Maatschappij voor Geschiedenis en Oudheidkunde te Gent. Uit vulgariserende werken en artikels werd slechts een keuze gemaakt. Een aantal niet opgenomen artikels en mededelingen kan men vinden in tijdschriften over heemkunde, toerisme, enz. Het opstellen van een volledige bibliografie vraagt heel wat opzoekingswerk. U kan het werk van de auteurs vergemakkelijken door uw boek of een overdruk van uw artikel te sturen aan het Stadsarchief, Abrahamstraat 13,9000 Gent. Het toegestuurde exemplaar zal ingeschreven worden in de bibliotheek van het Stadsarchief.
} 
1890-1891. Zingende Vogels 1891-1896. De Goedendag 1891-1901. De Jonge Vlaming 1894-1895. Andere tijdschriftinitiatieven aan de R.U.G. en de Vlaamse athenea, (Rijksuniversiteit. Cultureel Documentatiecentrum. Bibliografie van de Vlaamse Tijdschriften in de Negentiende Eeuw), Gent, 1990, 399 blz.

Met inleiding, auteurs- en trefwoordenregisters.

5. DE HERDT R. en J. VANNIEUWENHUYSE, Bibliografie van de geschiedenis van Gent 1988-1989, in HMGOG, XLIII, (1989), p. 231-271.

6. DEPREZ A. en H. VANACKER, Vlaemsche Volks-Almanak, 1845-1848. Volks-Almanak van bet Willemsfonds, 1853-1880. Lovensche Kerssouwieren-Almanak, 1861-1866. Jaarboekje van het Kerssouwken, 1867-1874. Letterkundige Bijdragen van bet Kersouwken, 1896-1913. Gelegenbeidsbundels van bet Kerssouwken, 1851/1855/ 1871/1923, (Rijksuniversiteit. Cultureel Documentatiecentrum. Bibliografie van de Vlaamse Tijdschriften in de Negentiende Eeuw), Gent, 1990,180 blz.

De Vlaemsche Volks-Almanak en de Volks-Almanak van het Willemsfonds, die bibliografisch ontleend worden, sluiten aan bij de rijke Gentse traditie van almanakken of informatief-literaire jaarboekjes. Met auteurs- en trefwoordenregisters.

7. DEVOLDER J., Algemene bibliografie van publicaties uitgegeven in de Zuidelijke Nederlanden voor de periode 1800-1829, (Rijksuniversiteit Gent. Centrale Bibliotheek. Bijdragen tot de Bibliotheekwetenschap, VI), Gent, 1989, 3 dln., XX + 1884 blz.

8. Het kunstpatrimonium te Drongen 1973-1990. Catalogus, (Dienstencentrum), Drongen, 1990, 64 blz. Geillustreerd.

9. NUYTTENS M., Het archief van de Staten van Vlaanderen als bron voor de lokale vorser, in Liber Amicorum Achiel De Vos, Evergem, 1989 , p. $151-154$.

10. VAN GOETHEM G., Een gebeugen van papier. Gids voor de archieven van $A M S A B,(A M S A B)$, Gent, 1989, z.blz.

Overzicht van de archieven, die op het AMSAB ontsloten zijn voor het wetenschappelijk onderzoek. Van elk afzonderlijk archief worden beschreven: archiefvormer, vormelijke en inhoudelijke aspekten, de verwerkingsstaat en raadplegingsvoorwaarden, verwijzingen naar aansluitende dokumentaire bestanden en bibliografie. Met voorwoord, inleiding en verschillende indices.

11. VERKERKEN D., Sint-Stefanus, Augustijnenklooster Gent. Register der begravingen (1783-1797), Gent, z.d., z.blz.

Alfabetische naamlijst van het begraafboek.

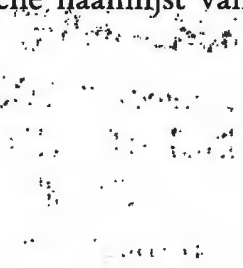


12. VERKERKEN D., Sint.Stefanus, Parocbie Gent. Doopregister (1803-1816), buwelijkenregister (1803-1828), register der begravingen (1803-1818), Gent, z.d., 3 dln., z.blz.

Alfabetische naamlijsten van de parochieregisters.

Algemeen

13. Gent: 300 jaar geneeskunde, (Faculteit Geneeskunde RUG en UZG), Gent, 1990, 107 blz.

Kataloog van een tentoonstelling rond de organisatie en het onderwijs in de geneeskunde te Gent tussen 1663 (= de oprichting van het Collegium Medicum) en 1930 ( = de vernederlandsing van de universiteit). Met woord vooraf door M. THIERY en illustraties. Zie ook: R. VAN HEE (ed.), In de voetsporen van Yperman. Heelkunde in Vlaanderen door de eeuwen been, Brussel, 1990, 389 blz.

14. POELMAN R., Misdaad en straf in het oude Gent, in De OostOudburg. Jaarboek, XXVI, (1989), p. 17-90.

Overzicht van het strafrecht, de soorten misdaden en de bestraffing te Gent door de eeuwen heen. Geillustreerd.

\section{Archeologie}

15. BAUTERS L. en J. BOURGEOIS, Houtbouw in de prebistorie in de provincie Oost-Vlaanderen, in HMGOG, XLIII, (1989), p. 5-27.

Vooral de opgravingen in Sint-Denijs-Westrem waren van bijzonder belang voor de kennis van het architekturaal leefmilieu tot voor de komst van de Romeinen. Met plannen.

16. CALLEBAUT D., M.C. LALEMAN en P. RAVESCHOT, Onderzoek van bet Gravensteen in Gent (O.Vl.), in Archaeologia Mediaevalis, 13, (1990), p. 19-20.

17. DE PAEPE P. en F. VERMEULEN, Archeo-petrografisch onderzoek van natuursteen gevonden in enkele Gallo-Romeinse nederzettingen uit bet Gentse, in VOBOV-Info, (1988-1989), nr. 32-33, p. 1-15.

Studie over het gebruik en verhandelen van natuursteen in de GalloRomeinse nederzettingen van Asper, Eke, Huise, Sint-DenijsWestrem en Sint-Martens-Latem. Geillustreerd.

18. DE WITTE H., M.C. LALEMAN en T. OOST, Stadsarcheologie in Vlaanderen, in J.L. MEULEMEESTER (red.), Vlaamse archeologie. Opgravingen in binnen - en buitenland. Tentoonstellingscatalogus, Oudenburg, 1990, p. 45-50. Geillustreerd.

19. ERVYNCK A., Archeozoölogisch onderzoek op bet laboratorium van paleontologie (R.U.G.), in Archaeologig Mediaeruglis. 13 (1990) p. 9-12

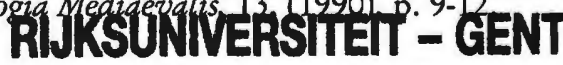

SEMINARIE VOOR ALGEMENE EN

INSTITUTIONELE GESCHIEDENIS

DER MIDDELEEUWEN

Blandijnberg 2 - 9000 GENT 
Met korte nota over het onderzoek van beenderresten uit het Ryhovesteen te Gent.

20. ERVYNCK A., Botmateriaal uit de Kammerstraat. Een steekproef in middeleeuws keukenafral ?, in Stadsarcheologie, 14, (1990), nr. 2, p. 45-48. Geillustreerd.

21. ERVYNCK A., Zwarte ratten bevolkten eens het Patershol. De mummies uit Rodekoningstraat 5, in Stadsarcheologie, 14, (1990), nr. 2, p. 32-37. Geillustreerd.

22. GAUTIER A., Dierlijke resten uit een kuil in bet Hof van Rybove te Gent (eerste belft 13de eeuw), in Stadsarcheologie, 14, (1990), $\mathrm{nr} .1$, p. 50-53. Geillustreerd.

23. GOUBITZ O., Ledervondst uit de Belfortstraat-Kammerstraat, in Stadsarcheologie, 14, (1990), nr. 2, p. 42-44. Geillustreerd.

24. LALEMAN M.C. en J. DE BOECK, Archeologisch textiel uit de Gentse Sint-Niklaaskerk, in Stadsarcheologie, 13, (1989), nr. 4, p. 5-8. Geïllustreerd.

25. LALEMAN M.C. en P. RAVESCHOT, Stadsarcheologisch onderzoek te Gent (O.-Vl.), in Archaeologia Mediaevalis, 13, (1990), p. 48-50.

Overzicht van de archeologische prospekties in 1989 en van de voornaamste onderzoeksresultaten. Geillustreerd.

26. RAVESCHOT P., Een middeleeuwse schoenmaker in de Kammerstraat, in Stadsarcheologie, 14, (1990), nr. 2, p. 39-41.

27. RAVESCHOT P. en R. VAN DE WALLE, Een kuil onder bet Hof van Rybove, in Stadsarcheologie, 14, (1990), nr. 1, p. 45-49.

Korte bespreking van de gevonden potscherven (13de eeuw), waarvan de meerderheid scherven in rood aardewerk waren. Geillustreerd.

28. SORBER F., Textiel uit een rattennest (Patershol, Gent), in Stadsarcheologie, 14, (1990), nr. 2, p. 38.

29. VANDENBERGHE S., Een merkwaardige ceramische vondst aan het Sint-Veerleplein in Gent, in Stadsarcheologie, 13, (1989), nr. 4, p. 2-4. Het betreft de basis van een smeltkroes uit de 15 de eeuw met de afdruk van een dubbele groot. Met foto.

30. VAN STRYDONCK M., Verslag radiokoolstofdateringen beenderen Sint-Niklaaskerk, in Stadsarcheologie, 13, (1989), nr. 4, p. 9-10. Geïllustreerd.

31. VERMEULEN F., Kelten, Romeinen en Germanen tussen Leie en Schelde. Archeologische vondsten in Sint-Martens-Latem en in bet zuiden 
van de Vlaamse zandstreek, in Heemkring Scheldeveld. Jaarboek, XVIII, (1989), p. 3-117.

Verslag van de opgravingen te Sint-Martens-Latem (Brakel) en overzicht van de huidige stand van het onderzoek betreffende de voor- en vroeghistorische bewoning in het gebied ten zuidwesten van Gent tussen Leie en Schelde. Geillustreerd.

32. Vondstmeldingen, in Stadsarcheologie, 13, (1989), nr. 4, p. 11-33. Meldingen van: muurresten in de Belfortstraat en $\mathrm{Bij}$ Sint-Jacobs; resten van een laat-middeleeuws huis in de Cataloniëstraat 1; archeologisch onderzoek aan de Houtlei en grachtrand in de Drabstraat -Jan Breydelstraat; archeologische steekproef in Drongenhof-kapel; resten van 2 middeleeuwse huizen bij het Vleeshuis, Groentenmarkt; middeleeuwse konstrukties, Hoogpoort 60; muurresten, Jan Breydelstraat 3-5; aanvulling op de bewoningsgeschiedenis van Kammerstraat 4 met gegevens uit de 20ste eeuw; muurresten in Klein Turkije 14; twee middeleeuwse konstrukties in de Koningstraat 12; muurresten, Korenmarkt 17; een gebouw in zandsteen, Korenmarkt 18-19; muurfragmenten Korte Kruisstraat en Langemunt 40; twee konstrukties in de Nodenaysteeg; "loove" in de Onderstraat 10; middeleeuws huis in de Onderstraat 28; kontrolegraving in binnentuin stadhuiskomplex, Poeljemarkt; archeologisch onderzoek op het parkeerterrein aan de Schepenhuisstraat; muurresten in Doornikse kalksteen, SintBaafsplein 10; archeologisch onderzoek bij restauratiewerken aan het Gravensteen, Sint-Veerleplein; laatmiddeleeuwse wenteltrap en traptoren, Speldenstraat 1; prospektie van resten van het Utenhovesteen onder de Vrijdagmarkt 9; bodem- en muurwerkonderzoek, Waaistraat 1; merk NPN op vensterdorpel Kasteel Achtendries, Orchideestraat 51 Oostakker.

33. Vondstmeldingen, in Stadsarcheologie, 14, (1990), nr. 1, p. 54-56.

Meldingen van: bodemonderzoek in de Ziekenzaal van de voormalige Bijloke-abdij; oost-west verlopende natuurstenen muur in de Godshuizenlaan; muurresten in Doornikse steen (KetelpoortNederkouter) en prospektie kelders Hotel Falligan (Kouter 172).

34. Vondstmeldingen, in Stadsarcheologie, 14, (1990), nr. 2, p. 49-55. Bondige bespreking van het bodemonderzoek in de Ziekenzaal van de voormalige Bijloke-abdij; menselijk botmateriaal van het Oud Kerkhof buiten de Brugsepoort (Gebroeders De Smetstraat); koperen plaatje met heraldisch motief in de Goudstraat 12; houten palissade op de vroegere Spriet, Kortrijksepoortstraat-Sint Kwintensberg; gevelstenen met inskriptie 1631 in Onderbergen 86; opgravingen buiten het Prinsenhof op de terreinen van de voormalige fabriek Van AckerVan den Broecke in verband met Donkere Poort en omheiningsmuur; bouwkundige ontwikkeling donjon Gravensteen en cirkelvormige schrabber in vuursteen te Drongen (BourgoyenValkenhuis). 
Middeleeuwen

35. BOONE M., De souverein baljuw van Vlaanderen: breekijzer in bet conflict tussen stedelijk particularisme en Bourgondische centralisatie, in Handelingen van het Genootschap voor Geschiedenis te Brugge, 126, (1989), nr. 1-2, p. 57-78.

36. BOONE M., Geld en macht. De Gentse stadsfinanciën en de Bourgondische staatsvorming (1384-1453), (Verbandelingen der MGOG, XV), Gent, 1990, 260 blz.

Indringende analyse van de stedelijke boekhouding, de financiën en de fiskale politiek die door het stadsbestuur gevoerd werd. Met bijlagen en Engelse samenvatting.

37. BOONE M., Gent en de Bourgondische bertogen ca. 1384-ca. 1453. Een sociaal-politieke studie van een staatsvormingsproces, (Verbandelingen van de Koninklijke Academie voor Wetenschappen, Letteren en Schone Kunsten van België. Klasse der Letteren, nr. 133), Brussel, 1990, 281 blz. De drie leden (poorterij, weverij en kleine neringen) beheersten in de beschouwde periode het politiek-maatschappelijke leven te Gent. Hun partikularisme kwam in botsing met de centralisatie-opvattingen van de hertogen. Met grafiek, kaart, organogrammen, samenvatting en index.

38. BOONE M., Triomferend privé-initiatief versus haperend overheidsoptreden? Over pachters van indirecte belastingen in laatmiddeleeuwse steden, in Tijdschrift voor Sociale Geschiedenis, 15, (1989), nr. 2, p. 113-138.

De laatmiddeleeuwse steden verwierven de meeste financiële middelen uit indirekte verbruiksbelastingen. De inning ervan werd doorgaans verpacht. Aan de hand van Gentse gegevens werden deze belastingspachters nader bestudeerd. Met tabellen en grafiek.

39. DANNEEL M., Orphanhood and marriage in fifteenth-century Ghent, in W. PREVENIER (ed.), Marriage and social mobility in the late middle ages, (Studia Historica Gandensia, 274), Gent, 1989, p. 99-111. De Gentse schepenen van gedele zorgden voor een rechtvaardige verdeling van de sterfhuizen met minderjarige wezen. Wanneer deze wezen later een huwelijk wensten af te sluiten traden de schepenen eveneens op.

40. DE HEMPTINNE T. en A. VERHULST, De oorkonden der graven van Vlaanderen (juli 1128 - september 1191). Deel II/band 1, Regering van Diederik van de Elzas (juli 1128 - 17 januari 1168), (Koninklijke Commissie voor Geschiedenis. Verzameling van de akten der Belgische vorsten, 6), Brussel, 1988, XCVIII +522 blz. Geïllustreerd. 
41. D'HOOGHE C. en E. BALTHAU, Een bijdrage tot de studie van bet stadspatriciaat in de late middeleeuwen : de Brugse familie De Vos in de 14de-15de eeuw, in Castellum, VI, (1989), nr. 2, p. 4-81.

De familie De Vos, die een uitgebreid grond- en goederenbezit verwierf - onder meer ook de heerlijkheid Laarne - kende een Gentse vertakking langs Boudin IV de Vos. Geillustreerd.

42. LIEVOIS D., De wijnteelt in Gent volgens Idrisi, in Van rank tot drank, Brussel, 1990, p. 72-73.

43. MESTDAGH M.(†), De Vikingen bij ons. Het Grote Leger (879-892) in België en Frankrijk, (Stichting Mens en Kultuur), Gent, 1989, 303 blz. Vanuit Fulham (Engeland) staken de Vikingen in 879 over naar het vasteland en legden een winterkamp aan in Gent, van waaruit dan verdere tochten ondernomen werden. In de daarop volgende jaren werden ook op ander plaatsen in het huidige België en Frankrijk telkens volgens eenzelfde patroon Vikingkampen aangelegd. Uit vele van deze kampen blijken zich de middeleeuwse steden ontwikkeld te hebben. Met voorwoord door prof. em. R. DE BOCK-DOEHAERD en illustraties.

44. PREVENIER W., Confiscatie van Gentse leliaards in 1314-1316, in Liber Amicorum Achiel De Vos, Evergem, 1989, p. 155-159.

Tijdens het heropflakkerend konflikt tussen Vlaanderen en Frankrijk in 1314-1316, liet de Vlaamse graaf de goederen van de leliaards konfiskeren. Heel wat Gentse namen uit het konfiskatiedossier zijn in verband te brengen met families die rond 1300 reeds als leliaard bekend waren.

45. THOEN E., Een model voor integratie van bistorische geografie en ekonomische strukturen in Binnen-Vlaanderen. De bistorische evolutie van het landschap in de Leiestreek tussen Kortrijk en Gent tijdens de middeleeuwen, in Heemkring Scheldeveld. Jaarboek, XIX, (1990), p. 3-34. Geillustreerd.

46. TRIO P., Armenzorg te Gent. Een onderzoek naar de steunverlening aan armen bij de broederschappen in de late middeleeuwen, in Liber Amicorum Achiel De Vos, Evergem, 1989, p. 181-187.

De broederschappen die gevestigd waren in de parochie- en kloosterkerken steunden in hoofdzaak de eigen leden bij behoeftigheid of ziekte.

47. VAN CAENEGEM R.C., De Gentse justitiekeure van 1294: een commentaar, in Liber Amicorum Achiel De Vos, Evergem, 1989, p. 189-195.

De keure van 1294 werd gezamenlijk uitgevaardigd door graaf Gwijde van Dampierre en de magistraat. Ze bevat duidelijke afspraken betreffende de jurisdiktie van de schepenen over de stad en buiten het 
schependom. Daarnaast omschrijft ze de rechten van de landvorst. Geillustreerd.

48. VANDEVENNE G., De middeleeurese stad ... méér dan een nederzetting, Kortrijk, 1990, 85 blz.

Kataloog van een tentoonstelling over de middeleeuwse stadsontwikkeling in Vlaanderen. Geillustreerd.

49. VERHULST A., The origins of towns in the Low Countries and the Pirenne-thesis, in Past and Present, 122, (1989), p. 3-35. Met kaarten.

\section{Moderne Tijden}

50. BRAEKMAN W.L., Belezers, waarzeggers en beksen te Gent in de zestiende en zeventiende eeur, in Oostvlaamse Zanten, LXV, (1990), nr. 1, p. 3-12.

Uittreksels uit de Gentse "crime"-boeken betreffende toverij en hekserij.

51. BROUWER A. en I. VELLEKOOP, De mazen van het net. Vlaardingse en Maassluisse schepen onder Oostenrijkse vlag tijdens de Vierde Engelse Oorlog, in Historisch Jaarboek Vlaardingen, 13, (1989), p. 81-92.

Ten gevolge van de oorlog, die begon op 20 december 1780, viel de visserij in Vlaardingen en Maassluis stil. De schippers trachtten hun boten opnieuw in de vaart te brengen door het kopen van het poorterschap en het verwerven van zeebrieven in de Zuidnederlandse steden, vooral dan in Gent. Hierdoor kon onder Oostenrijkse - en dus neutrale - vlag gevaren worden. Geillustreerd.

52. BUNTINX J., De luitenant-civil van de indaginghe van Gent, in Liber Amicorum Achiel De Vos, Evergem, 1989, p. 61-66.

Op 14 februari 1541 stelde keizer Karel V het luitenant-civilschap in. Een nieuwe vorstelijke ambtenaar diende als rechter op te treden in burgerlijke geschillen tussen Gentenaars en inwoners van 66 plattelandslokaliteiten.

53. CRAEYBECKX J., Een Gentse garentwijnder tussen boom en crisis. Het bedriffjoernaal van Charles Soenens (1659-1673), in Actief in arcbief. Huldeboek Hilda Coppejans-Desmedt, (Vlaamse Vereniging voor Bibliotheek-, Archief- en Documentatiewezen. Archiefkunde, 4), Antwerpen, 1989, p. 23-38.

De boekhouding van Soenens is illustratief voor de organisatie en de werking van een Gents pre-industrieel garentwijnbedrijf. Bovendien toont ze de strategie van de ondernemer in voorspoed (tot 1663) en in krisistijd (vanaf 1664). 
54. DAMBRUYNE J., Conjunctuur, stratificatie en koopkracht te Gent tijdens de eerste belft van de 17 de eeur. De economiscbe en sociale betekenis van de rente- en woningmarkt, in HMGOG, XLIII, (1989), p. 129-158. Door het bestuderen van de ontwikkelingen op de Gentse rente- en immobiliënmarkt wordt het mogelijk om het stedelijk ekonomisch klimaat te meten. Met tabellen.

55. DECAVELE J. (red.), Keizer tussen stropdragers. Karel V 1500-1558, Leuven, 1990, $245 \mathrm{blz}$.

Monografie over keizer Karel V, de geschiedenis van de Lage Landen onder zijn regering en zijn haat-liefderelatie met de stad Gent. Bevat bijdragen van J. DAMBRUYNE, J. DECAVELE, J. DE ZUTTER, F. HEYMANS, J. VAN DE WIELE, J. VANNIEUWENHUYSE en P. VAN PETEGHEM. Met index van plaats- en persoonsnamen en illustraties. Zie ook: Gent en keizer Karel V. Het stadsbeeld in de 1ste belft van de 16de eeuw, (Het Toreken), Gent, 1990, $10 \mathrm{blz}$.

56. D'UDEKEM D'ACOZ J., Quelques aspects de la vie en Flandre au XVIIIe siècle, Gent, 1989, 541 blz.

De meeste aandacht gaat uit naar Gentse ontwikkelingen. Geillustreerd.

57. DUVOSQUEL J.M. (red.), Albums de Croÿ. Valleien van Samber en Leie, Brussel, 1989, 333 blz.

De albums werden eind 16de-begin 17de eeuw aangelegd door hertog Karel van Croÿ om een overzicht te verkrijgen van zijn uitgestrekte bezittingen. Het boekdeel bevat onder meer een inleidende beschrijving door E. THOEN over de Leie van Wervik tot Gent (57-71) en bekommentarieerde platen betreffende Gent (318-323). Geillustreerd.

58. LENDERS P., Gent, een stad tussen traditie en verlichting (1750-1787), (Standen en Landen, XCII), Kortrijk-Heule, 1990, 532 blz.

Reeds vóór de Brabantse Omwenteling waren te Gent duidelijk maatschappelijke veranderingen waarneembaar. Het spektakulairst op sociaal-ekonomisch (de beginnende industrialisering) en kultureel vlak. Niet minder belangrijk waren de hier beschreven institutionele vernieuwingen, die vooral onder impuls van voorschepen burggraaf Vilain XIIII doorgedrukt werden. Met diverse tabellen en index van persoons- en plaatsnamen.

59. LENDERS P., Sociale gevoeligheden en veranderende maatschappij te Gent circa 1770, in HMGOG, XLIII, (1989), p. 173-189.

De ekonomische inzinking met stijgende graanprijzen en een druk op de lonen in de jaren 1767-1775 veroorzaakte ook te Gent veel onvrede.

60. VAN DEN ABEELE R., De Horenbault-kaart van de Brugse Vaart (1615), in Liber Amicorum Achiel De Vos, Evergem, 1989, p. 197-206. 
Bespreking van een kaart vervaardigd door de Gentse kartograaf Jacques Horenbault. Geillustreerd.

61. VANDER PLAETSE K. en G. VERBEURGT, Voorbuwelijks seksueel gedrag te Gent 1700-1850, in Driemaandelijks Tijdschrift Gemeentekrediet, 44, (1990), nr. 172, p. 111-118.

62. VERSCHAFFEL T., Bernardus de Jonghe (1676-1749) en de Opstand. De geschiedenis van de Ghendtsche Geschiedenissen, in HMGOG, XLIII, (1989), p. 159-171.

De Gentse dominikaan De Jonghe publiceerde tussen 1743 en 1746 in afleveringen en in 1746 ook in boekvorm de Ghendtsche Geschiedenissen. Postuum werden in 1752 door De Roothaese en in 1781 door De Mulié gewijzigde versies op de markt gebracht.

\section{Hedendaagse Tijd}

63. Aspecten van het "Verzet" tijdens de Tweede Wereldoorlog, (Bijlokemuseum. 8 Mei Komitee), Gent, 1990, 27 blz. Geillustreerd.

64. BRUYNEEL F., De armenzorg en het hospice te Sint-Amandsberg. Deel 2, in De Oost-Oudburg. Jaarboek, XXVI, (1989), p. 111-130.

Behandelt de periode 1944-1977. Geillustreerd.

65. DE BLEECKER M. en W. DEVOS, Verweesd, verwezen. Vier eeurwen kulders, rode lijvekens en blauwe meisjes in Gent, Gent, 1990, 243 blz. Geschiedenis van de opvang en verzorging van weesmeisjes en jongens te Gent. Met voorwoord door gouverneur H. BALTHAZAR en illustraties.

66. DEPREZ P. en C. VANDENBROEKE, Population growth and distribution, and urbanization in Belgium during the demographic transition, in R. LAWTON en R. LEE (eds.), Urban population development in Western Europe from the late-eighteenth to the early-twentieth century, Liverpool, 1989, p. 220-257.

Beschrijving van de demografische evoluties in de 19de- en vroeg 20ste-eeuwse Belgische steden en vooral dan in Gent. Met tabellen, grafieken en kaart.

67. Gedenkboek 1964-1988. 25 jaar Feest van de Vrijzinnige Jeugd te Gent, Gent, 1988, 88 blz. Geillustreerd.

68. Het noodgeld van Oost-Vlaanderen tijdens W.O. I en W.O. II, (Nationale Bank van België), Brussel, 1989, 88 blz.

Kort na het uitbreken van Wereldoorlog I kende men een groeiend geldtekort. Vele gemeentebesturen voerden daarop zelf noodgeld in. De stad Gent gaf veruit het meest biljetten en metalen of kartonnen munten uit. Geillustreerd. 
69. KINT P., Prometheus aangevuurd door Demeter. De economische ontwikkeling van de landbouw in Oost-Vlaanderen 1815-1850, Amsterdam, 1989, XV + $460 \mathrm{blz}$.

Ingevolge de industriële omwenteling moest de ekonomie zich in Oost-Vlaanderen aanpassen. De traditionele linnennijverheid kreeg rake klappen te verduren. De landbouw daarentegen kende een gestage groei. Met kaarten.

70. LENDERS P., Lof voor Gent. De indrukken van de latere Amerikaanse president Jobn Quincy Adams over zijn verbliff in de Scheldestad in 1814, in Driemaandelijks Tijdschrift Gemeentekrediet, 44, (1990), nr. 171 , p. 23-29.

In 1814-1815 verbleef Adams gedurende zeven maanden in de stad. Hij leidde een Amerikaanse delegatie tijdens onderhandelingen met Groot-Brittannië. Geillustreerd.

71. RAES R. en A.M. SIMON-VAN DER MEERSCH, De bladen van de Vlaams-Nationale Studenten Unie Gent (1957-1981), met een inventaris van bet archief van de V.N.S.U., (Archief R.U.G. Uit bet Verleden van de R.U.G., nr. 29), Gent, 1989, 71 blz. Geillustreerd.

72. ROETS E., Comparatief onderzoek naar de zuigelingensterfte in Oosten West-Vlaanderen (begin 19de eeuw), in M. CLOET en C. VANDENBROEKE (red.), Tien bijdragen tot de lokale en regionale demografie in Vlaanderen, (Gemeentekrediet. Historische uitgaven, reeks in- $\left.8^{\circ}, n r .79\right)$, Brussel, 1989, p. 193-206.

De sterftecijfers van de zuigelingen tijdens de Franse en Hollandse periode worden in kaart gebracht per arrondissement. Verklaringen voor de verschillen worden gezocht bij de sociaal-ekonomische en kulturele toestanden in de besproken regio's. Met kaarten en tabellen.

73. Sint-Paulusinstituut, Broeders van Liefde Patijntjestraat. Vijtig jaar bumaniora, Gent, 1989, 132 blz. Geillustreerd.

74. STOCKMAN R., Het leven binnen de muren van bet Guislaininstituut (1850-1950), in Ghendtsche Tydinghen, 19, (1990), nr. 2, p. 58-76. Overzicht van het leven binnen het Guislaingesticht met personalia over Maximilianus Meijssem (1818-1903), Alexander van Peteghem (1806-1874), Benjamin-Constant Inghels (1830-1886), Florus Lauwagie (1878-1960), Joris Eeckhout (1887-1951), Karel van Acker (1895-1975) en Oscar Colbrandt (1879-1959). Geilllustreerd.

75. VANACKER D., Het Vlaamsch Liberaal Persbureau (1907-1914), in Wetenschappelijke Tijdingen, XIVIII, (1989), nr. 1, p. 1-25.

76. VERMEULEN A.M., Structuuranalyse van een stedelijke populatie. Gent in de 19de eeuw, in M. CLOET en C. VANDENBROEKE (red.), Tien bijdragen tot de lokale en regionale demografie in Vlaande. 
ren, (Gemeentekrediet. Historische uitgaven, reeks in $\left.-8^{\circ}, n r .79\right)$, Brussel, 1989 , p. 247-261.

Doorlichting van de 19de-eeuwse stadsbevolking. Besproken worden: de migratie, de natuurlijke bevolkingsbeweging en de bevolkingssamenstelling. Met tabellen.

\section{Kerkgeschiedenis, kloosters}

77. BERINGS G. en C. LEBBE, Abbaye de Saint-Bavon à Gand, in Monasticon belge. Tome VII, Province de Flandre Orientale. Premier volume, (Nationaal Onderzoekscentrum voor Religieuze Geschiedenis), Luik, 1988, p. 11-67.

Bevat een overzicht van de opeenvolgende benamingen van de abdij en van de beschikbare bronnen voor de studie van de abdijgeschiedenis. Zowel de geschreven als de niet-geschreven bronnen, zoals de sigillografie, de ikonografie, de epigrafie en de heraldiek worden behandeld. Met een historische nota en biografieën van de abten.

78. BERINGS G. en C. VAN SIMAEY, Abbaye de Saint-Pierre au MontBlandin à Gand, in Monasticon belge. Tome VII, Province de Flandre Orientale. Premier volume, (Nationaal Onderzoekscentrum voor Religieuze Geschiedenis), Luik, 1988, p. 69-154.

Bevat de opeenvolgende benamingen van de abdij, een overzicht van de bronnen voor de rekonstruktie van de abdijgeschiedenis, een historische nota en biografieën van de abten.

79. BRAEKMAN E.M., Les fondateurs du Synode, in Bulletin de la Société d'Histoire du Protestantisme belge, (1989), nr. 103, p. 1-80.

Op 22 en 23 april 1839 werd te Brussel de Bond der Protestants Evangelische Kerken van het koninkrijk België gesticht door afgevaardigden van de lokale protestantse kerkraden. Gent was op de stichtingsbijeenkomst vertegenwoordigd door predikant Albert Goedkoop en door de kerkraadsekretaris Gerard Jan Westendorp. Het bestuursorgaan van de Bond werd de Synode genoemd. Geîllustreerd.

80. CASSIMAN P., Sint-Regina godshuis te Baarle, in Dronghine. Jaarboek, (1990), p. 33-45.

Historiek van het neogotisch godshuis voor ouderlingen en zieken, dat ingehuldigd werd in 1874. Geillustreerd.

81. DAEM M., Het Sint-Jacobsgodshuis te Gent, in Oostvlaamse Zanten, LXIV, (1989), nr. 2, p. 113-129.

Historiek van het godshuis. Onder meer worden behandeld: de stichting en de organisatie, het uitzicht, de gebouwen en de likwidatie van de instelling. Geillustreerd. 
82. DAEM M., Mirakelverbalen uit de O.-L.-Vrouwkerk op St.Pieters te Gent. Manuskripten van de mirakelverbalen, in Oostvlaamse Zanten, LXV, (1990), nr. 1, p. 33-50.

Overzicht van de 14 bewaard gebleven verhalen. Met illustratie. Het twaalfde verhaal werd gedetailleerd beschreven in ID., Exorcisme in de O.-L.-Vrouwkerk op St.-Pieters te Gent. Livina vander Plasche van drie duivels verlost. Februari 1652, in Oostvlaamse Zanten, LXV, (1990), nr. 1, p. 13-32.

83. DECLERCQ G., Nieuwe inzichten over de oorsprong van bet SintVeerlekapittel te Gent, in HMGOG, XLIII, (1989), p. 49-102.

De Sint-Veerlekerk werd als burchtkerk in de eerste helft van de 10de eeuw gesticht. Ten laatste sedert 1073 waren een aantal sekuliere geestelijken er werkzaam. Tussen 1202/1204 en 1207 werd de priestergroep omgevormd tot kapittel.

84. GYSSELING M., De oudste annalen van de Sint-Baafsabdij, in De Oost-Oudburg. Jaarboek, XXVI, (1989), p. 5-16.

In een afschrift uit 1570 of kort erna bleven annalen bewaard betreffende de Sint-Baafsabdij. Zij dateren van ca. 1030. De auteur beoordeelt de waarde ervan en bespreekt de gegevens die ze bevatten voor de kennis van de vroege abdijgeschiedenis. Als slot wordt er een transkriptie gebracht, voorzien van een Nederlandse vertaling.

85. HENDRIX G., Bernardina en Cisterciensia in de Universiteitsbibliotheek, (Rijksuniversiteit Gent. Schatten van de Universiteitsbibliotbeek, 7), Gent, 1990, XVIII + 254 blz.

Kataloog bij een tentoonselling van werken geschreven door Bernardus van Clairvaux en van boeken en handschriften met betrekking tot de Gentse cisterciënzerkloosters. Met woord vooraf door hoofdbibliothekaris A. VANDEN BRANDE en konservator A. DEROLEZ, inleidend artikel door prof. L. MILIS en illustraties.

86. HÖDL L. en M. HAVERALS (eds.), Henrici de Gandavo. Tractatus super facto praelatorum et fratrum (Quodlibet XII, quaestio 31), (Ancient and Medieval Philosophy. De Wulf-Mansion Centre, series 2), Leuven, 1989, CLXIX + 292 blz.

87. LEHOUCQ N., De Mariale bedevaart in de 19de eeuw. Dadizele Oostakker - Scherpenbeuvel. Funktionele en tijdsgebonden aspekten, in Oostvlaamse Zanten, LXIV, (1989), nr. 4, p. 253-269.

Omtrent de betekenis van de Maria-bedevaarten voor de kerkelijke overheden, de plaatselijke gemeenschappen en de individuele gelovigen. Geillustreerd.

88. STEEGHERS W., Overleden begijntjes en personen van het GrootBegijnhof Sint-Elisabeth te Gent afkomstig uit Lokeren, in Vlaamse Stam, 25, (1989), nr. 10, p. 481-483. 
89. STEEGHERS W., Overleden begijntjes van bet Groot Begijnhof SintElisabeth te Gent afkomstig van Bassevelde en Watervliet in de 18de eeuw, in De Eik, 14, (1989), nr. 2, p. 75-76.

90. STEEGHERS W., Overleden begijntjes van bet Groot-Begijnhof SintElisabeth te Gent afkomstig van Watervliet in de 18de eeuw, in De Levensboom. Informatieblad V.V.F. Meetjesland, 3, (1990), nr. 3, p. 15.

91. STEEGHERS W. en J. VANNIEUWENHUYSE, De Gentse geestelijkbeid en de verklaringen van onderwerping aan het regime gedurende de Franse tijd, 1797-1804, in Vlaamse Stam, 25, (1989), nr. 10, p. 498-508. Geillustreerd.

92. STEEGHERS W. en J. VANNIEUWENHUYSE, Ledenlijst van de Protestantse Kerk te Gent uit 1849, in H.R. BOUDIN (red.), Belgische Protestantse Biografieën, (PRODOC), II, (1989), losbladige fichen.

93. TRIO P., De Gentse broederschappen (1182-1580). Ontstaan, naamgeving, materiële uitrusting, structuur, opheffing en bronnen, (Verbandelingen der MGOG, XVI), Gent, 1990, $270 \mathrm{blz}$.

De besproken 40 Gentse broederschappen waren ondergebracht in parochiekerken, hospitaalkapellen en in klooster-of abdijkerken. $\mathrm{Ze}$ hadden tot doel het zieleheil van de leden te bevorderen. Met bijlagen en indices van persoonsnamen, plaatsnamen, instellingen, ikonografie en patroonschappen.

94. VERHULST A., Note sur deux chartes de Lothaire, roi de France, pour l'abbaye de Saint-Bavon à Gand, in Handelingen van de Koninklijke Commissie voor Geschiedenis, CLV, (1989), afl. 1-2, p. 1-23.

Diplomatische en inhoudelijke studie van twee akten uit 954 en 966. In de eerste wordt de aanstelling van Wido tot abt van Sint-Baafs bevestigd, de tweede akte bevestigt algemeen de restauratie van de abdij door graaf Arnulf.

\section{Industriële Archeologie}

95. BODE M., De industriële ontwikkeling van Gentbrugge, in Driemaandelijks Tijdschrift Land van Rode, 17, (1989), nr. 3, p. $48-54$ en nr. 4, p. 75-81. Geillustreerd.

96. DE KEUKELEIRE E., Evolutie van het openbaar vervoer in bet Gentse, in Tijdschrift voor Geschiedenis van Techniek en Industriële Cultuur, 8, (1990), nr. 1, p. 9-39.

97. GALLOO J., 150 jaar geleden. De spoorlijn Kortrijk-Gent werd een feit, in De Leiegouw, XXXI, (1989), afl. 3, p. 149-166.

De spoorlijn werd plechtig geopend op 22 september 1839. Geïllustreerd. 
98. Industrieel netwerkmuseum Gent. Wandelingen, nr. 1, Gent, 1989, 99 blz.

Uitgave verwezenlijkt ter gelegenheid van de tentoonstelling "Bouwen voor de industrie", ingericht door het Museum voor Industriële Archeologie en Textiel van 21 april 1989 tot 25 juni 1989. Met beschrijving van: De katoenroute van Gent door T. EECKHOUT en G. DESEYN; Rondom de Minnemeersgracht: ontwikkeling van een vroeg-industriële site door G. DESEYN; Van Sint-Baafs tot de Zuid: stedebouwkundige en industrieel-archeologische ontwikkeling van een stadswijk door L. VAN SCHOORS en J. VAN DE WIELE; Bier en brouwerijen te Gent door J. VAN DE WIELE. Geillustreerd.

99. KERCKHAERT N. en D. DE VLEESCHAUWER, Het nieuwe licht uit Langerbrugge 1900-1940, Tielt, 1990, 493 blz.

Van ca. 1900 af kende het gebruik van elektriciteit in Vlaanderen een doorbraak. Tal van lokale vennootschappen stonden in voor de bevoorrading. In 1911 werd de Centrales Electriques des Flandres opgericht. Vooral vanuit de Centrales van Langerbrugge (1914) en Zeebrugge (1925) werd voortaan de elektriciteit verdeeld. In 1928 fusioneerden de Vlaamse en Brabantse elektriciteitsvennootschappen tot Centrales Electriques des Flandres et du Brabant. Geilllustreerd. Zie ook ID., Het nieuwe licht uit Langerbrugge (1900-1940). Catalogus bij de tentoonstelling, 1990, z.blz.

100. LIEVOIS D., Wijn en industrialisering. "Un gentilhomme-verrier" in de XVIIIe eeuw, in Van rank tot drank, Brussel, 1990, p. 282-287. Historiek van 18 de-eeuwse flessenbedrijven in Brugge en Gent. Geïllustreerd.

101. RUMMENS M., O.I.P. R.I.P., in Tijdschrift voor Geschiedenis van Techniek en Industriële Cultuur, 8, (1990), nr. 2, p. 24-35.

Historisch overzicht van het Gentse bedrijf voor optische instrumenten O.I.P., gesticht door André Callier in 1919. Geillustreerd.

\section{Gebouwen, monumenten, stadsbeeld}

102. BAILLIEUL B. en A. DUHAMEEUW, Een stad in opbouw. Gent vóór 1540, Tielt, 1989, 335 blz.

Studie over de bouwaktiviteit in de stad vóór 1540. Met bijdragen van M. BOONE, R. DE HERDT en F. VAN TYGHEM. De eindredaktie berustte bij G. VAN DOORNE. Het boek bevat verder een woord vooraf door de voorzitter van de Nationale Confederatie Bouwbedrijf R. MAES en een inleiding door gouverneur H. BALTHAZAR. Geillustreerd.

103. BAILLIEUL B. en W. OERS, De oranjerie, startsein van de wereldbefaamde Gentse Floraliën, in De Woonstede door de Eeuwen been, (1990), nr. 85 , p. 59-65. 
De bloemenkwekers richtten oranjerieën in om hun exotische planten te laten overwinteren. Geïllustreerd.

104. BAUTERS P., Kracht van wind en water. Molens in Vlaanderen, Leuven, 1989, 288 blz. Geilllustreerd.

105. BECKER U., Studien zum flämischen Altarbau im 17. und 18. Jabrbundert, (Verbandelingen van de Koninklijke Academie voor Wetenschappen, Letteren en Schone Kunsten van België. Klasse der Schone Kunsten, nr. 49), Brussel, 1990, 180 blz.

Met onder meer aandacht voor altaren in de Gentse Sint-Baafskathedraal. Geilllustreerd.

106. BOERJAN G., L. COLLIN en D. SMET, Honderd Gentse OnzeLieve-Vrouwe-kapelletjes, ("Gent aan Maria"), Gent, 1988, z.blz. Geïllustreerd.

107. BRAL G.J., Kunsthistorische begeleiding bij restauratieprojecten van bistorische interieurdecoratie: een noodzaak, in Vlaanderen, 38, (1989), nr. 4. p. 10-18.

Als voorbeeld wordt de restauratie van het Gentse dominikanenklooster (Onderbergen) besproken. Geillustreerd.

108. BRUYNEEL G., Het Meershof op de Achterdries, in Driemaandelijks Tijdscbrift Land van Rode, 18, (1990), nr. 1, p. 5-11.

Betreft het Hof Bruyneel in Gentbrugge. Met illustraties.

109. COGEN H., De Muide. Wandeling Gentse Feesten 1989, in G.O.V. Heraut, 25, (1990), nr. 3, p. 25-38. Geilllustreerd.

110. COGEN H., De Vismijn. Een terugblik op 300 jaar geschiedenis, in G.O.V.-Heraut, 24, (1989), nr. 6, 18 blz. Geillustreerd.

111. COGEN H., Ekkergem, een volksbuurt bij uitstek, in G.O.V.-Heraut, 25, (1990), nr. 4, p. 39-54.

112. COGEN H., Wandeling van de Graurepoort tot Muidepoort, in G.O.V.-Heraut, 25, (1990), nr. 2, 24 blz. Geillustreerd.

113. DAEM M., Het Chinese salon in het Hotel d'Hane-Steenbuyse te Gent. Beschilderd behangselpapier uit de 18de eeuw, in De Woonstede door de Eeuwen heen, (1989), nr. 82, p. 23-36. Geïllustreerd.

114. DE BUCK R., Een gevelbeeld voor een legende: Liederick de Buck, in Ghendtsche Tydinghen, 19, (1990), nr. 1, p. 21-24.

Het beeld bevindt zich in een nis van het stadhuis. Met foto.

115. DE GROOTE S., De parochiekerk van Oostakker wordt gerestaureerd, in Heemkundig Nieures, 18, (1990), nr. 2, p. 2-5. Geillustreerd. 
116. DE MEYER D., Henry van de Velde en de Bibliotbeek van de Gentse Rijksuniversiteit, in Interbellum, 10, (1990), nr. 3, p. 6-9. Geillustreerd.

117. DE PERMENTIER C., De Heirniswijk. Wandeling Gentse Feesten 1989, in G.O.V.-Heraut, 25, (1990), nr. 5, p. 55-72. Geillustreerd.

118. DESEYN G., Huis Rossel: een onbekende realisatie van bet architectenvennootschap F. Bodson en A. Pompe te Gent, in Interbellum, 10, (1990), nr. 2, p. 5-7. Geillustreerd.

119. DE SMET Y., De restaurateur ter tafel gebracht, in Interbellum, 9, (1989), nr. 3, p. 6-7; nr. 4, p. 5-7; nr. 5, p. 4-7; 10, (1990), nr. 1, p. 5-7 en nr. 4 , p. 5-7.

Bevat biografische gegevens over de kunstminnaar professor-dokter Adriaan Martens (Bocholt, 1885-Astene, 1968) en een bespreking van zijn woonhuis te Astene, thans omgebouwd tot restaurant. Geillustreerd.

120. DEVOS P. en L. ROBIJNS, Beschermde monumenten, stadsgezichten en dorpsgezichten, in Kultureel Jaarboek voor de Provincie OostVlaanderen, 42, (1988), p. 145-151.

Voor Gent zijn te vermelden: huizenrij Graaf van Vlaanderenplein 1-37 en Zuidstationstraat 33-37, voormalig redaktiegebouw van het dagblad Vooruit, huis Minard en Minardschouwburg.

121. DE WIT J.M. en G. VAN DOORNE, Restaureren in OostVlaanderen, Verbond van de Kringen voor Heemkunde in OostVlaanderen), Wichelen, 1989, 159 blz.

Bespreking van de door het Verbond bekroonde restauraties tijdens de periode 1973-1988. Met voorwoord door verbondsvoorzitter R. RUYS en inleiding door gouverneur H. BALTHAZAR. Geillustreerd.

122. Een verdwenen kasteel, in Driemaandelijks Tijdschrift Land van Rode, 18, (1990), nr. 1, p. 12-18 en nr. 2, p. 28.

Betreft het Braunkasteel te Gentbrugge. Geillustreerd.

123. ESTHER J.-P., Orde en maat in het Gentse classicisme. De Gulden Snede bij 18de-eeuwse gevelontwerpen, in Stadsarcheologie, 14, (1990), nr. 1 , p. 4-44.

Aan de hand van talrijke architektuurontwerpen wordt aangetoond dat de verhouding van de Gulden Snede in het 18de-eeuwse Gent bekend was en graag werd toegepast als middel om een harmonische gevelordonnantie te bekomen. Geillustreerd.

124. FREDERICQ-LILAR M., Een verleidelijk rococo-kunstwerk in Gent: de eetkamer van het voormalig Hotel de Coninck, in Vlaanderen, 38, (1989), nr. 4, p. 29-32. 
Voor de inrichting van de eetkamer in 1768 deed Ferdinand de Coninck beroep op de beeldhouwer Frans Allaert en de kunstschilder Pieter Norbert van Reysschoot. Geïllustreerd.

125. Gent. Open monumentendag, Gent, 1989, z.blz.

Voorstelling van het etnografisch en archeologisch museum van de R.U.G. en van een aantal monumenten: de Minardschouwburg, het Feestpaleis Vooruit, het Emmaüskasteel, de buitentuin van de SintPietersabdij, de watertorens van de Kattenberg, de SintKwintenskapel en de Centrale Bibliotheek van de R.U.G. Met woord vooraf door schepen R. VAN QUAQUEBEKE en illustraties.

126. Gent. Open monumentendag, Gent, 1990, $60 \mathrm{blz}$.

Op de monumentendag kon men de universiteitsaula, de boekentoren en verschillende kloosters, kapellen en kastelen bezoeken. Van elk gebouw wordt een korte beschrijving gepubliceerd. Met woord vooraf door schepen R. VAN QUAQUEBEKE en illustraties.

127. HENDRYCKX M., M. DE KOONING en B. VERSCHAFFEL, Gent, de gedeelde stad, Brugge, 1990, $167 \mathrm{blz}$.

Fotoboek voorzien van begeleidende teksten van B. VERSCHAFFEL (9-14) en M. DE KOONING bij de foto's van M. HENDRYCKX. Met voorwoord door schepen R. VAN QUAQUEBEKE en ten geleide.

128. HOSTE L., Rooigem en de Brugsepoort te Gent, in Ghendtsche Tydinghen, 19, (1990), nr. 3, p. 114-127; nr. 4, p. 205-219 en nr. 5, p. 266-270.

De geschiedenis van de Rooigemwijk. Geillustreerd.

129. HOSTE L., Uithangborden te Gent (vervolg en slot), in Ghendtshe Tydinghen, 18, (1989), nr. 6, p. 312-317. Geillustreerd.

130. Hotel d'Alcantara. Opnieuw een historisch pand bedreigd te Gent: het Hotel d'Alcantara in de Gouvernementstraat, in De Woonstede door de Eeuwen been, (1990), nr. 85, p. 57-58. Geïllustreerd.

131. Inventaire Archéologique - Fiche Nr. 78. De Werkklok van het Belfort, in Ghendtsche Tydinghen, 19, (1990), nr. 5, p. 260-261. Geillustreerd.

132. Inventaire Archéologique - Fiche Nr. 155. Bas-reliëfs van het zogenaamde buis Palfijn, in Ghendtsche Tydinghen, 19, (1990), nr. 4, p. 193-194. Geilllustreerd.

133. Inventaire Archéologique - Fiche Nr. 388. Het Wachttorentje van Ter Platen, in Ghendtsche Tydinghen, 19, (1990), nr. 3, p. 128-129. Geïllustreerd. 
134. JANSSENS S., Het Meerhemkanaal, in Ghendtsche Tydinghen, 19, (1990), nr. 3, p. 134-147.

Het Meerhemkanaal vormde de verbinding tussen de Leie en de Blaisantvest enerzijds en het Tolhuisdok anderzijds. Geillustreerd.

135. KLUYSKENS P., De "Fransche Theater", in Ghendtsche Tydinghen, 19, (1990), nr. 5, p. 261-265. Geillustreerd.

136. LABYN M., Uit de geschiedenis van de Gentse bruggen, in Ghendtsche Tydinghen, 18, (1989), nr. 6, p. 332-338; 19, (1990), nr. 1, p. 13-21; nr. 2, p. 88-93; nr. 3, p. 149-159; nr. 4, p. 219-230 en nr. 5, p. 292-296. Geîllustreerd.

137. MAES D., Een monument voor Karel Waeri, in Dronghine. Jaarboek, (1990), p. 2-9.

Het standbeeld van de volkszanger Waeri (Gent, 1842-1889) werd vervaardigd door Walter de Buck en bevindt zich Bij Sint-Jacobs. Geïllustreerd.

138. POELMAN R., Een opmerkelijke gedenkzuil op bet Campo Santo, in Heemkundig Nieuws, 18, (1990), nr. 1, p. 1-6.

Omtrent de herinneringsobelisk van de oud-wapenbroeders onder Napoleon. Geillustreerd.

139. VAN AERDE R. (†), De kazerne op de Kattenberg, nu de "Leopold", Gent, z.d., 38 blz.

Heruitgave van een artikel uit Ghendtsche Tydinghen, vermeerderd met diverse illustraties.

140. VAN CLEVEN J., Het boudoir of de zgn. "Blauwe Kamer" in bet Hotel Lousbergs-de Hemptinne in Gent, in Vlaanderen, 38, (1989), nr. 4, p. 33-36.

De textielbaron Ferdinand Lousbergs liet in 1842 onder de leiding van architekt L. Eyckens een woning optrekken aan de Keizer Karelstraat. Pronkstuk ervan werd het boudoir. Geillustreerd.

141. VAN DOORNE G., De wedergeboorte van bet Hof van Rybove, in Toerisme in Oost-Vlaanderen, 38, (1989), nr. 4, p. 96-99. Geilllustreerd.

142. VAN TYGHEM F., Een middeleeuws burgerinterieur te Gent. De Arsenaalzaal van bet Stadbuis, in Vlaanderen, 38, (1989), nr. 4, p. 19-21. Geillustreerd.

143. VAN WASSENHOVE R., Het Rijke Gasthuis en bet klooster der dominicanen. Historische en chronologische situering van bet kloostercomplex vanaf 1146 tot 1989, in G.O.V.-Heraut, 25, (1990), nr. 1, 6 blz. Met plattegronden.

RIJKSUNIVERSITEIT - GENT SEMINARIE VOOR ALGEMENE EN INSTITUTIONELE GESCHIEDENIS DER MIDDELEEUWEN 
144. VAN WITTENBERGHE O., De Bassijnwijk tussen de twee wereldoorlogen, in Driemaandelijks Tijdschrift Land van Rode, 17, (1989), nr. 3, p. 55-69.

145. Wandelen in de Sint-Niklaasparochie, (Dienst Monumentenzorg en Stadsarcheologie), Gent, 1990, 32 blz. Geillustreerd.

Kunst, kultuur

146. ANSEEUW M., Meesters in het rijk der tonen. Het Koninklijk Muziekconservatorium Gent en bet Nieuwe Klankschap, Gent, 1989, 187 blz. In veertien gesprekken met leraars wordt gepeild naar het verleden en de toekomst van het Gentse conservatorium. Tussentekstjes beschrijven het conservatoriumgebouw en andere getuigenissen uit het verleden. Het boek wordt afgesloten met een kroniek (1812-1988). Geillustreerd.

147. BRAUSCH P., Turnkring Ganda: een militante Vlaamse sportvereniging tijdens bet Interbellum, in Wetenschappelijke Tijdingen, XLIX, (1990), nr. 2, p. 65-83.

148. CAPITEYN A. en M. MUSSCHOOT, De strip van Gent, (Dienst voor Culturele Zaken), Gent, 1990, 80 blz.

Overzicht van Gents geschiedenis in een stripverhaal.

149. DE BIE-DE BRUYCKERE H., Het kanten kleed van keizerin MariaTheresia, zoals afgebeeld op het schilderij dat zich in bet Stadhuis van Gent bevindt, in G.O.V.-Heraut, 24, (1989), nr. 3, 8 blz. Geillustreerd.

150. DE BUCK R., 51 blazoenen van ridders in de Orde van bet Gulden Vlies, in Ghendtsche Tydinghen, 19, (1990), nr. 3, p. 147-149 en nr. 4, p. 182-193.

Geromantiseerde voorstelling van het laatste kapittel van het Gulden Vlies, gehouden te Gent op 23, 24 en 25 juli 1559.

151. DE HERDT R., Gentse Floraliën. Sierteelt in Vlaanderen, (Stichting Mens en Kultuur), Gent, 1990, X + 326 blz.

Overzicht van de ontwikkeling van de tuinbouw sinds de vroege middeleeuwen en van de sierteelt te Gent sinds de 19de eeuw. Gewezen wordt onder meer op de belangrijke rol van de Koninklijke Maatschappij voor Landbouw en Plantkunde en van de Floraliën. Met ten geleide door graaf DE KERCHOVE DE DENTERGHEM, inleiding door gouverneur H. BALTHAZAR, nawoord door schepen R. VAN QUAQUEBEKE en illustraties. Zie ook ID., Een floraliënwandeling doorheen Gent, in Toerisme in Oost-Vlaanderen, 39, (1990), nr. 1, p. 6-11 en Gent een stad van bloemen vroeger en nu. Wandelingen en we- 
tenschappelijke bijdragen, (Industrieel netwerkmuseum Gent. Wandelingen, nr. 2), Gent, 1990, 80 blz.

152. DEPREZ A. (red.), Karel van de Woestijne. Verzameld journalistiek werk. Vijfde deel, (Cultureel Documentatiecentrum), Gent, 1990, 724 blz.

153. DE RIDDER J.H.A., Gerechtigheidstaferelen voor schepenbuizen in de Zuidelijke Nederlanden in de 14de, 15de en 16de eeur, (Verbandelingen van de Koninklijke Academie voor Wetenschappen, Letteren en Schone Kunsten van België. Klasse der Schone Kunsten, nr. 45), Brussel, 1989, $182 \mathrm{blz}$.

Als Gentse gerechtigheidstaferelen worden besproken: een Laatste Oordeel uit 1413 door L. vanden Clite (thans in het Stedelijk Museum van Diest), een Laatste Oordeel uit 1589 door R. Coxcie (thans in het Museum voor Schone Kunsten te Gent) en een onthoofdingsscène uit 1608 door P. Pieters (thans in het Bijlokemuseum te Gent). Geillustreerd.

154. DE VOS J., Het toneelleven te Gent 1987-1988, in Kultureel Jaarboek voor de Provincie Oost-Vlaanderen, 42, (1988), p. 60-64. Met illustraties.

155. DE VOS J., 15 jaar Arca, 1975-1990. Theater als zoektocht, Gent, 1990, 96 blz. Geillustreerd.

156. DE VRIENDT-MORES R. en R. VAN DE WALLE, Emile van Vooren, huisbewaarder en beschermbeer van Gentse kunstenaars, in Oostvlaamse Zanten, LXV, (1990), nr. 2, p. 95-104.

Van Vooren (Waarschoot, 1849-Gent, 1921) was huisbewaarder van de universitaire Aula en beschermer der Schone Kunsten. Geïllustreerd.

157. DE ZUTTER J., Collega's van het Wonderkind. Muziekleven te Gent in Mozarts tijd, in Toerisme in Oost-Vlaanderen, 39, (1990), nr. 3, p. 59-64. Geillustreerd.

158. DE ZUTTER J., Het wapen van Gent, (Stadsarchief), Gent, 1990, 40 blz.

$\mathrm{Bij}$ gemeenteraadsbesluit van 23 april 1990 werd het Gentse stadswapen gewijzigd. In de brochure worden de verschillende bestanddelen van het wapen geanalyseerd. Geillustreerd. Zie ook ID., Het nieuwe stadswapen van Gent. Maagd en leeuw in trouw en liefde, in Toerisme in Oost-Vlaanderen, 39, (1990), nr. 2, p. 39-42.

159. Gentse penningen 1780-1980, (Dienst voor Culturele Zaken. Museum voor Volkskunde), Gent, 1989, 203 blz. 
Tentoonstellingskataloog gewijd aan de penningen vervaardigd in opdracht van het Gentse stadsbestuur en/of door Gentse kunstenaars. Met diverse inleidende teksten en indices van persoonsnamen, plaatsnamen, verenigingen en feestelijkheden. Geîllustreerd.

160. GYSSELING M., De leliester van de burggraven van Gent, heren van Heusden, in De Oost-Oudburg. Jaarboek, XXVI, (1989), p. 192-200. De burggraven voerden in hun wapen een gouden achtarmige leliester met in het midden een rode umbo op een zwart veld. Geillustreerd.

161. Het Museum Arnold Vander Haeghen, in G.O.V.-Heraut, 24, (1989), nr. 2, p. 21-24.

162. HOOZEE R. (red.), Vlaams expressionisme in Europese context 1900-1930, (Museum voor Schone Kunsten), Gent, 1990, 398 blz.

Gentse kunstenaars zoals G. Minne, G. van de Woestijne, C. Permeke, A. Servaes, G. de Smet, F. Masereel, F. van den Berghe, H. Malfait, Jozef en Jan Cantré worden onder meer voorgesteld en in de kunsthistorische ontwikkelingen van hun tijd gesitueerd. Met bijdragen van P. BOYENS, I. HENNEMAN, R. HOOZEE, H. LAUWAERT en W. VAN DEN BUSSCHE, voorwoord door schepen R. VAN QUAQUEBEKE en illustraties.

163. HUYS P., "Zegen-prael van Keyser Carel den VI". Een toneelopvoering in Drongen in 1764, in Drongbine. Jaarboek, (1990), p. 92-101. Geïllustreerd.

164. Inventaire Archéologique - Fiche Nr. 202. Het Tabernakel van de St.Jacobskerk, in Ghendtsche Tydinghen, 19, (1990), nr. 2, p. 76-78.

165. Inventaire Archéologique - Fiche Nr. 210. Miniaturen van Cornelis Horenbaut, in Ghendtsche Tydinghen, 18, (1989), nr. 6, p. 310-311.

166. Inventaire Archéologique - Fiche Nr. 225. Grotesk ijzeren masker, in Ghendtsche Tydinghen, 19, (1990), nr. 1, p. 12-13. Geillustreerd.

167. Koninklijke Kunst- en Letterkundige Kring - Cercle Royal Artistique et Littéraire 110, 1879-1989, Gent, (1989), 215 blz.

Historiek van de Kring, die op 4 mei 1879 ontstond uit de samensmelting van de Société Littéraire en het Kunstgenootschap. Bedoeling was het Gentse kulturele leven te bevorderen door het inrichten van lezingen, tentoonstellingen en muziekopvoeringen. Met illustraties.

168. MARTENS M.P.J., De muurschilderkunst te Gent (12de tot 16de eeuw), (Verhandelingen van de Koninklijke Academie voor Wetenschappen, Letteren en Schone Kunsten van België. Klasse der Schone Kunsten, nr. 46), Brussel, 1989, 286 blz. 
Worden achtereenvolgens behandeld: het ontstaan en de werking van de schildersambachtsgilde, de techniek van het muurschilderen met aansluitend de konserveringsproblematiek, de ikonografie en het architekturaal kader van de schilderingen. Vervolgens zijn alle bekende Gentse muurschilderingen afzonderlijk beschreven en besproken. Geillustreerd.

169. Musea Gent. Musées de Gand. Genter Museen. Museums of Ghent, (Stad Gent), Gent, 1989, 93 blz.

Voorstelling van de belangrijkste stedelijke en niet-stedelijke musea. Met woord vooraf door schepen R. VAN QUAQUEBEKE, ten geleide door J. DECAVELE, Franse, Duitse en Engelse samenvattingen. Geillustreerd.

170. MUSSCHOOT A.M. (ed.), Karel van de Woestijne. Aan de boogste kim, (Poëziecentrum), Gent, 1989, $250 \mathrm{blz}$.

Een keuze uit de poëzie van Van de Woestijne. Met inleiding, verantwoording van de uitgave, levenskronologie en selektieve bibliografie.

171. Ook dit gebeurde in Oost-Vlaanderen, in Kultureel Jaarboek voor de Provincie Oost-Vlaanderen, 42, (1988), p. 181-186.

Gentse tentoonstellingen in 1988 : De Markt (M.I.A.T.), Signaturen (Museum van Hedendaagse Kunst), Pretiosa Neerlandica (Centrale Bibliotheek R.U.G.), Architektuur als buur (D.M.S.A. en Architektuurpromotie), Gent in weelde herboren. Wereldtentoonstelling 1913 (Stadsarchief) en Historie op perkament (Stadsarchief). Geillustreerd.

172. PEETERS F., Jan Oscar de Gruyter en bet Vlaamse Volkstoneel 1920-1924. Een theaterhistoriografische studie, Vlaams Theater Instituut), Leuven, 1989, $568 \mathrm{blz}$.

Het Vlaams Volkstoneel was een rondreizend katholiek theatergezelschap met De Gruyter als kunstleider. In het boek worden de eerste vier speeljaren van het gezelschap gedetailleerd bestudeerd, gesitueerd in het toenmalige theatersysteem en geplaatst tegenover de politieke, sociaal-ekonomische en kulturele ontwikkelingen. Met illustraties.

173. Portret van Jeanne Bauwens-van Peteghem, Gent 1741-Gent 1802 door François Joseph Kinsoen (Brugge 1770-1839), in G.O.V.-Heraut, 25, (1990), nr. 2, 2 blz.

174. POULAIN N., A. RIGELLE en E. RIGELLE, Het kunstwerkhuis van glasversieren G. en H. Rigelle, (Interbellum. Cabier, 5), Gent, 1989, 39 blz. Gustave Rigelle (Gent, 1908-1981) was een kunstenaar die vooral bekendheid verwierf met zijn zandstraaltechniek en een atelier uitbouwde. Geillustreerd. Zie ook W. PATOOR en R. DE VOCHT, G. Rigelle, in Driemaandelijks Tijdschrift Land van Rode, 17, (1989), nr. 2, p. 30-33. 
175. POULAIN N., J. VANDENBROUCKE en M. VAN MULLEM, Joris Vandenbroucke en het poppenspel, (Interbellum. Cabier, 6), Gent, $1990,40 \mathrm{blz}$.

Priester Vandenbroucke (Maldegem, 1896-Gent, 1980) stichtte het poppenspeltheater Spelleke van de Muide. Geillustreerd.

176. Restauratie is rijkdom, (Dienst Monumentenzorg en Stadsarcheologie), Gent, 1989, $47 \mathrm{blz}$.

Over het Hof van Ryhove en de restauratieproblematiek van de schilderijen die leden van de familie Ryhove voorstellen (17de-20ste eeuw). Geillustreerd.

177. ROOSEN J.P., Antoon van den Heuvel 1600-1677, in G.O.V.-Heraut, 25, (1990), nr. 2, 2 blz.

Bespreking van het schilderij "Aanbidding der herders".

178. STALLAERTS R. en B. HOGENKAMP, Rode glamour. Bioscoop, film en socialistische berweging, (Provinciebestuur Oost-Vlaanderen. Bijdragen Museum van de Vlaamse Sociale Strijd, nr. 6), Gent, 1989, 88 blz. Geillustreerd.

179. TAILLAERT P., Victor Stuyvaert. Illustrator, Brugge, 1990, z.blz. Overzicht van de in druk verschenen boeken, geillustreerd door Stuyvaert (Gent, 1897-1974). Met biografische schets van de kunstenaar door N. POULAIN en foto.

180. VAN DEN KERKHOVE A. (red.), Het voorlaatste van de grote Hollandse oorlogsscheepsmodellen. Geschiedenis en restauratie, (Bijlokemuseum), Gent, 1990, 96 blz.

Bevat bijdragen van N. KERCKHAERT, Enkele notities over de scheepsbouw te Gent tijdens het Ancien Regime (11-16), van A. VAN DEN KERKHOVE, De geschiedenis van het oorlogsscheepsmodel van het Bijlokemuseum (17-21) en van W. BIRNIE, De restauratie van het oorlogsscheepsmodel (22-62). Met een te geleide door schepen R. VAN QUAQUEBEKE, beschrijvingen van de tentoongestelde stukken en illustraties.

181. VAN ELSLANDE R., De predella: "De verovering van Jeruzalem door Titus", in Ghendtsche Tydingben, 19, (1990), nr. 4, p. 195-205. Bespreking van een predella uit de 16de eeuw, afkomstig uit de romaanse krypte van de Sint-Baafskathedraal, maar nu bewaard in het Museum voor Schone Kunsten te Gent. Geillustreerd.

182. VAN ELSLANDE R., Een Verrijzenis van Raphaël van Coxie, in Drongbine. Jaarboek, (1990), p. 119-133.

Abt Frans Schautheet schonk in 1588-1589 de verrijzenistriptiek voor het hoogaltaar van de kapel in de refuge van Drongen te Gent. Geïlustreerd. 
183. VAN ELSLANDE R., Het retabel van Cornelis Boone in opdracht van de mecenas Nicolaas van der Zickelen en de kerkmeesters voor de kerk te Nazareth, in Heemkring Scheldeveld. Jaarboek, XIX, (1990), p. $35-48$.

In 1477 kreeg de Gentse beeldhouwer Boone de opdracht een retabel te vervaardigen met de voorstelling van de Vijf Blijde Mysteriën van Maria voor de kerk te Nazareth. Het retabel werd tijdens de 16deeeuwse Beeldenstorm vernield. Geillustreerd.

184. 40 jaar Gentse oratoriumvereniging, in Kultureel Jaarboek voor de Provincie Oost-Vlaanderen, 42, (1988), p. 90-91. Geillustreerd.

185. 550 jaar schietspelen van de Sint-Jorisgilde, (Het Toreken), Gent, 1990, $18 \mathrm{blz}$.

Heemkunde, volkskunde, genealogie

186. A.A. Gent 1864-1989, Gent, 1989, z.blz. Geilllustreerd.

187. Beklach van de Dulle Griete, in Ghendtsche Tydinghen, 19, (1990), nr. 3 , p. $159-163$.

Tekst van een lied uit 1745 .

188. BOMBAY J., De Halewijnstraten te Drongen, in Dronghine. Jaarboek, (1990), p. 10-18. Geillustreerd.

189. BOMBAY J., De Koninklijke Muziekmaatschappij De Zwanezonen van Drongen 1910-1990, Drongen, 1990, 133 blz. Geillustreerd.

190. BOMBAY J., Twee priesters Daens te Drongen, in Dronghine. Jaarboek, (1990), p. 46-48. Geillustreerd.

191. BROGET G., Over d'Hane-Steenbuyse, Lodewijk XVIII en Chateaubriand, in Ghendtsche Tydinghen, 19, (1990), nr. 5, p. 238-259. Met illustraties.

192. CASSIMAN P., De Drongense conscrits, in Dronghine. Jaarboek, (1990), p. 137-142.

193. CELIS G., Volkskundige kalender voor het Vlaamsche Land, (Stichting Mens en Kultuur), Gent, 1990, $24+336+52$ blz.

Reprint van de kalender uit 1923 door priester Celis (Gent, 1880-1959). Met inleiding door R. VAN DER LINDEN en illustraties.

194. COLLUMBIEN H., Straatnamen in Gent, in Ghendtsche Tydinghen, 19, (1990), nr. 2, p. 100-101. 
195. DAEM M., Reuzenliederen in Oost-Vlaanderen, (Koninklijke Bond der Oostvlaamse Volkskundigen), Gent, 1989, 141 blz. Geillustreerd.

196. DE BAETS H., De landelijke post te Zwijnaarde, in Heemkring Scheldeveld. Jaarboek, XVIII, (1989), p. 119-135. Geillustreerd.

197. DE BUCK A., De gard'civik, in G.O.V.Heraut, 25, (1990), nr. 4, 4 blz.

198. DE BUCK R., De Concessio Carolina, in Ghendtsche Tydinghen, 19, (1990), nr. 2, p. 85-88.

199. DE BUCK R., De ex-burgemeester van Oudenaarde komt Gent versterken, in Ghendtsche Tydinghen, 19, (1990), nr. 3, p. 130-134.

Gegevens over de kalvinist François Cabelliau, heer van Mullem en tot 1580 burgemeester van Oudenaarde, die in 1583 het Gents poorterschap aannam en de Gentse Kalvinistische Republiek kwam versterken.

200. DE CLERCQ R., De inwoners van Afsnee in de commerciële repertoria van de 19e eeuw, in Heemkring Scheldeveld. Jaarboek, XVIII, (1989), p. 145-156. Geillustreerd.

Zie ook in hetzelfde jaarboek op p. 137-144 ID., De inwoners van de Scheldeveldgemeenten in de commerciële repertoria van de 19 e eeuw. Algemene inleiding.

201. DECLERCQ R., M. GRYPDONCK en V. KELDERMANBAUWENS, Onze kwartierstaat : Roger Dhondt (Gent, 23 juni 1916-Sint-Martens-Latem, 7 juni 1931), in Vlaamse Stam, 25, (1989), nr. 9, p. 435-444. Geillustreerd.

202. DEKEYSER E., Onze kwartierstaat : Alfons Haché (Gent, 1855-Gent, 1938), in Vlaamse Stam, 26, (1990), nr. 7-8, p. 389-396.

Haché was een sociaal strijder. Hij stichtte onder meer in 1890 de kristelijke metaalbewerkersbond van Gent. Met foto.

203. 30 jaar Transmissiecentrum. Stad Gent, Politie, Gent, 1990, 17 blz.

204. DESPRETZ A., Boddaert : een dynastie geneesheren, in Dronghine. Jaarboek, (1990), p. 56-86. Geillustreerd.

205. DESPRETZ A., Omtrent Gentse en andere hondepenningen. Een kynosematologische bijdrage, in Jaarboek van bet Europees Genootschap voor Munt- en Penningkunde, (1988), p. 37-92.

Beschrijvende lijst van $19 \mathrm{de}-$ en 20 ste-eeuwse belastings- en identifikatiepenningen voor honden. Geillustreerd.

206. 'Die de kruyden niet en kent komt bij broeder Jan naar Gendt". Curiosa uit de apothekerswinkel, (Het Toreken), Gent, 1990, 9 blz. 
207. ERVYNCK G., De Vlaamse Vereniging voor Familiekunde en Gent. Hoe bet begon, in V.V.F. Informatieblad-Afdeling Gent, 9, (1990), nr. 1 , p. 8-14.

208. Gentse liedjes, in Ghendtsche Tydinghen, 19, (1990), nr. 2, p. 97-99. Publikatie van een Gents St.-Niklaasliedje.

209. HERTELEER W., De stedelijke basisschool Klaverdries 50 jaar jong, in Dronghine. Jaarboek, (1990), p. 102-105. Geilllustreerd.

210. HOEBEKE G. en T. PENNEMAN, Sagen uit bet Land van Rode, in Driemaandelijks Tijdschrift Land van Rode, 18, (1990), nr. 2, p. 35-40.

211. HOSTE L., De poppenspelwereld van Gustje-Pierke-de Puydt, in Oostvlaamse Zanten, LXIV, (1989), nr. 3, p. 215-216.

Bespreking van een schilderij door J. Lagrou, bewaard in het Museum voor Volkskunde. Met foto.

212. HUYS P., Een kwartierstaat (Liebaert-Leuridan) in de Gazette van Gend (1790), in Vlaamse Stam, 26, (1990), nr. 7-8, p. 387-388.

213. HUYS P., Molenadvertenties in de "Gazette van Gend" (1782), in Molenecho's, 17, (1989), nr. 4, p. 179-180.

214. HUYS P., Oproepen tot erfgenamen in oude kranten, in Vlaamse Stam, 25 , (1989), nr. 11-12, p. 622-624; 26, (1990), nr. 1, p. 41-42 en nr. 2, p. 58-59.

Oproepen in de Gazette van Gend (1781-1782), die gebruikt kunnen worden bij het samenstellen van een stamboom.

215. JACOBS M., Volkskunde in het Interbellum. De Zuidnederlandse Centrale voor Folklore-onderzoek, een ontbrekende schakel ?, Gent, 1989, 95

blz.

Op 23 oktober 1932 werd te Brussel de Centrale gesticht. Bedoeling was alle feitenmateriaal van volkskundige aard te verzamelen, te bestuderen en te publiceren. De stuwende krachten van de vereniging waren P. de Keyser, F. Olbrechts en C. Trefois. Geillustreerd.

216. KLUYSKENS P., Lodewijk XVIII in Gent, in Ghendtsche Tydinghen, 19, (1990), nr. 2, p. 78-84. Met foto van de auteur.

217. LEVIS E., "Oaze k'ik ben den eeste prijs, kook mijn moeder pap mee rijs", in Ghendtsche Tydinghen, 19, (1990), nr. 5, p. 270-291.

Over belonen en straffen in het onderwijs. Geillustreerd.

218. LEVIS E., Van alle markten thuis, in Ghendtsche Tydinghen, 18, (1989), nr. 6, p. 318-331 en 19, (1990), nr. 1, p. 25-50. Geillustreerd. 
219. MAES D., De bende Van Hoe en Verstuyft, in Ghendtsche Tydinghen, 18, (1989), nr. 6, p. 338-344 en 19, (1990), nr. 1, p. 5-11. Met illustraties.

220. MAES D., De wonderbare genezing van Jacob Clou te Gent, in Ghendtsche Tydinghen, 18, (1989), nr. 6, p. 358-360.

221. MAES D., Drongenaren in het gildeboek van bet gilde van de gelovige zielen van Vinderhoute, in Dronghine. Jaarboek, (1990), p. 134-136. Geillustreerd.

222. MAES D., Het hongerjaar 1847, in Dronghine. Jaarboek, (1990), p. 87-91.

Uittreksels uit de Gazette van Gent.

223. MAES D., Het stond in de krant. Gazette van Gent - Zondag 25 juli 1847: waterfeest te Drongen, in Dronghine. Jaarboek, (1990), p. 32.

224. MAES D., Vliegtuigongevallen te Drongen, in Dronghine. Jaarboek, (1990), p. 111-118. Geillustreerd.

225. MAES M.C., De orde van het Gulden Vlies, in G.O.V.-Heraut, 24, (1989), nr. 2, 7 blz.

226. OSSIEUR E.G.R., De borgstellers in de staten van goed te Gent: een verwaarloosde genealogische bron, in Vlaamse Stam, 26, (1990), nr. 5, p. 293-307.

227. PATOOR W., Straten te Gentbrugge met een persoonsnaam, in Driemaandelijks Tijdschrift Land van Rode, 18, (1990), nr. 1, p. 19-21.

228. POELMAN R., Het Werk van de Akker te Sint-Amandsberg, in Heemkundig Nieuwes, 17, (1989), nr. 5, p. 6-16.

De sociale vereniging voor volkstuinders werd in 1932 te SintAmandsberg opgericht.

229. POELMAN R., Jef Crick en zijn Campo-Santo-uitgaven, in Heemkundig Nieuws, 18, (1990), nr. 1, p. 7-10.

230. POELMAN R., Pauselijke zoeaven in ons werkgebied, in Heemkundig Nieures, 17, (1989), nr. 6, p. 2-7.

Betreft de zoeaven C.F.E. Mastraeten (Leuven, 1835-Destelbergen, 1895 ) en B. Farasijn (Meulebeke, 1843-Oostakker, 1913). Met illustraties.

231. ROOSEN J.P., De toeristische mogelijkheden van Sint-Amandsberg, in De Oost-Oudburg. Jaarboek, XXVI, (1989), p. 91-110. Geilllustreerd. 
232. SCHALCK-VAN DE VELDE C., Onze kwartierstaat : Placide de Paepe, minister van Sociale Voorzorg en burgemeester van Gent (AppelterreEichem, 1913-Gentbrugge, 1989), in Vlaamse Stam, 26, (1990), nr. 3-4, p. 145-148. Met foto.

233. STEEGHERS W., Curiosum uit de parochieregisters: begravingsakte van een doodgeslagen kind op 18 november 1789, begraven op het kerkbof van de augustijnen te Gent, in Vlaamse Stam, 25, (1989), nr. 9, p. 474. Geillustreerd.

234. STEEGHERS W., Personen overleden in bet Groot-Begijnhof SintElisabeth te Gent afkomstig uit Assenede, in De Levensboom. Informatieblad V.V.F. Meetjesland, 3, (1990), nr. 2, p. 13.

235. STEEGHERS W., Personen uit het Meetjesland, Lovendegem en Zomergem overleden in bet Bijlokehospitaal te Gent (1625-1799), in De Eik, 14, (1989), nr. 2, p. 71-74.

236. STEEGHERS W., Personen uit bet Meetjesland overleden op de $H$. Kerstparochie en op de Sint-Niklaasparochie te Gent (1685-1796), in De Eik, 14, (1989), nr. 2, p. 77-79.

237. STORME J., La Belle Epoque in oude prentkaarten, in De Draeke, 12, (1988-1989), nr. 1, p. 13-17; nr. 2, p. 33-38; nr. 3, p. 49-53; nr. 4, p. $84-89$; 13, (1989-1990), nr. 1, p. 22-27; nr. 2, p. 16-21; nr. 3, p. 11-16 en nr. 4, p. 4-11.

238. VAN BOST F., Prentkaartenrubriek, in De Draeke, 12, (1988-1989), nr. 4, p. 77-80; 13, (1989-1990), nr. 1, p. 13-17 en nr. 2, p. 13-15. Geïllustreerd.

239. VANDENBULCKE J., Voelde Keizer Karel zich Gentenaar en verklaarde bij ooit dat hij Gentenaar was ?, in G.O.V.-Heraut, 24, (1989), nr. 3, 14 blz. Geillustreerd.

240. VANGANSBEKE J., Achterdorpkermis (1949-1959) of de Gentse feesten in Drongen, in Dronghine. Jaarboek, (1990), p. 22-31. Geillustreerd.

241. VERBEKE A., Een nieuwe uitgave van prentkaarten. Ecodeux, in De Draeke, 12, (1988-1989), nr. 4, p. 81-82.

Biografieën

242. Actief in archief. Huldeboek Hilda Coppejans-Desmedt, (Vlaamse Vereniging voor Bibliotheek, Archief- en Documentatiewezen. Archiefkunde, 4), Antwerpen, 1989, $205 \mathrm{blz}$. 
Hilda Coppejans (Gent, 1924) studeerde geschiedenis aan de R.U.G. Van 1958 tot 1968 was ze achtereenvolgens als archivaris-paleograaf en werkleider en van 1977 tot 1989 als departementshoofd verbonden aan het Rijksarchief te Gent. Met foto van de gevierde, voorwoord door de voorzitter van de sektie Archieven van de V.V.B.A.D. J. VERHELST en bio-bibliografie door M. NUYTTENS.

243. ANTHEUNIS G., Leo Baekeland, (Dienst Leefmilieu. Rijksuniversiteit), Gent, 1989, 83 blz.

Baekeland (Gent, 1863-Beacon/New York, 1944) was foto-chemicus en vooral uitvinder van de kunststof "bakeliet". Met woord vooraf door schepen J. LEPEAU, verantwoording door prof. F. LOX en illustraties.

244. BRAUNS M., Hans Melen, in Oostvlaamse Literaire Monografieën, IX, (1989), p. 65-96.

Hans Melen - pseudoniem voor Frank van Doorne (Deinze, 1914-Gent, 1988) - schreef poëzie en essayistisch proza. Geïllustreerd.

245. BUYLE M., Eugène Joseph Verboeckhoven (1799-1881), in Heemkundig Nieuws, 18, (1990), nr. 3-4, p. 7-10.

Verboeckhoven (Waasten, 1799-Schaarbeek, 1881) was een landschaps- en dierenschilder die tussen 1815 en 1827 te Gent verbleef. Geïllustreerd.

246. BUYLE M., Gustaaf den Duyts (1850-1897), in Heemkundig Nieures, 18, (1990), nr. 2, p. 6-9.

Nota over de schilder Den Duyts (Gent, 1850-Brussel, 1897). Met illustraties.

247. BUYLE M., Jacques Bergmans, in Heemkundig Nieures, 17, (1989), nr. 6, p. 9-13.

Biografische schets van kunstschilder Bergmans (Gent, 1891-1959). Geillustreerd.

248. BUYLE M., Jean Joseph Delvin, kunstschilder-tekenaar, in Heemkundig Nieures, 17, (1989), nr. 5, p. 3-6.

Biografische nota betreffende de kunstenaar en akademieleraar Delvin (Gent, 1853-1922). Geillustreerd.

249. BUYLE M., Jozef Horenbant (1863-1956), in Heemkundig Nieures, 18, (1990), nr. 1, p. 10-13.

Levensschets van de kunstschilder Horenbant (Gent, 1863-SintNiklaas, 1956). Geilllustreerd.

250. BUYLE M., 50 Jaar geleden overleed kunstschilder en beeldhouwer Jozef Cornelis (Gent 1873-1840), in G.O.V.Heraut, 25, (1990), nr. 4, 2 blz. 
251. COLLIN L., De activiteiten van priester Adolf Daens vóór 1893 en de Daensistische beweging, in Drongbine. Jaarboek, (1990), p. 49-55.

Overzicht van de priesterloopbaan van Adolf Daens (Aalst, 1839-1907) voor zijn toetreding tot de Daensistische beweging. Geillustreerd.

252. COPPEJANS-DESMEDT H., De Schamp's, beren van Aveschoot, in Liber Amicorum Achiel De Vos, Evergem, 1989, p. 81-86.

Guillielmus Schamp (Gent, 1725-1798) kocht in 1781 de heerlijkheden Aveschoot en Bardelare in Lembeke. Geillustreerd.

253. DEGRYSE K. (ed.), Pieter Seghers. Een koopmansleven in troebele tijden, Antwerpen-Baarn, 1989, 149 blz.

Seghers (Gent, 1551-1621) was achtereenvolgens als koopman aktief in Londen, Cadiz, Sevilla en Antwerpen. Van 1590 af verbleef hij opnieuw in Gent en bracht het er verschillende keren tot schepen van de keure. In het boek wordt een 16de-eeuws autobiografisch handschrift van Seghers in hertaling uitgegeven, voorzien van een uitvoerige inleiding over het leven en het werk van de auteur. Met illustraties.

254. DE ROO U., Beeldhouwer Mathias Zens en de neo-gotiek 1839-1989, z.pl., 1989, 76 blz.

Mathias Zens (Schwarzenborn, 1839-Gent, 1921) volgde de Gentse Sint-Lukasschool en leverde beeldhouwwerk voor verschillende kerken in de stad. Geillustreerd.

255. DE TRAZEGNIES M., E.H. Deken Daniel de Trazegnies (1912-1980), in Heemkundig Nieures, 18, (1990), nr. 5, p. 12-18.

De Trazegnies was vanaf 26 oktober 1969 pastoor van de SintAmandusparochie en deken in Sint-Amandsberg. Geillustreerd.

256. DE VISSCHER-D'HAEYE B., Hippolyte Daeye 1873-1952. Genese van een oeuvre, Brussel, 1989, 303 blz.

Daeye (Gent, 1873-Antwerpen, 1952) volgde lessen aan de Akademie te Gent en aan het Instituut voor Schone kunsten te Antwerpen. Hij schilderde vooral kinderen en naakten. Geillustreerd.

257. DE VOCHT R., De heer Henri Errynck, in Driemaandelijks Tijdschrift Land van Rode, 18, (1990), nr. 2, p. 25-26.

258. DE VOLDER B., Paul-Gustave van Hecke, in Oostvlaamse Literaire Monografieën, IX, (1989), p. 161-192.

Van Hecke (Gent, 1887-Elsene, 1967) was bedrijvig als toneelschrijver, dichter, prozaschrijver en essayist. Hij werd ook bekend als galerijhouder en promotor van de moderne schilderkunst. Met illustraties.

259. DIERICK A., José de Poortere. "Zonder beelden duizel ik", in Oostvlaamse Literaire Monografieën, IX, (1989), p. 33-64. 
De Poortere (Sint-Niklaas, 1935-) publiceerde tot hiertoe negen dichtbundels, twee romans, enige kortverhalen en essays. Geilllustreerd.

260. FRANCOIS L., Jean-Baptiste d'Hane de Steenbuyse (Gent, 1757-Gent, 1826), een conservatief edelman tussen Ancien Régime en Hedendaagse Tijd, in HMGOG, XLIII, (1989), p. 191-210.

261. GYSSELING M., De heilige Bavo, in Heemkundig Nieures, 18, (1990), nr. 3-4, p. 3-6.

Levensbeschrijving van Bavo, die zich tot het kristendom bekeerde in 647-650 onder invloed van Amandus. Hij verbleef tijdelijk te Mendonk en overleed in zijn kluis te Gent kort vóór 659. Op de plaats van de kluis verrees later de Sint-Janskerk (thans Sint-Baafskathedraal).

262. Herdenkingstentoonstelling Helene de Reuse 1892-1979, (Beschermkomitee Campo Santo. Het Toreken), Gent-Sint-Amandsberg, 1989, z.blz. Kataloog van een retrospektieve tentoonstelling over De Reuse (Wachtebeke, 1892-Mariakerke, 1979), die portretten en stillevens tekende of schilderde. Geillustreerd. Zie ook L. LEKENS, Kunstschilderes Helene de Reuse 1892-1979, in G.O.V.-Heraut, 24, (1989), nr. 6, p. 19-24.

263. Herdenkingstentoonstelling Hendrik Caspeele 1889-1983, (Het Toreken. Dokumentatiecentrum voor Dramatische Kunst), Gent, 1990, 29 blz. De toneelauteur, -akteur en -regisseur Caspeele (Gent, 1889-SintMartens-Latem, 1983) was onder meer van 1940 tot 1944 direkteur van de Koninklijke Stadsopera Gent. Met woord vooraf door F. DEMEDTS en illustraties.

264. HOFLACK K., Theo Leferve staatsman, Antwerpen-Baarn, 1989, 122 blz.

Biografie van de politicus Lefèvre (Gent, 1914-Sint-LambrechtsWoluwe, 1973). Geïllustreerd.

265. HUYS P., Over de "negende" (maar niet van Beethoven!). De Drongense koster-organist-komponist J. de Vreese, in Dronghine. Jaarboek, (1990), p. 19-21.

Biografische gegevens over De Vreese (Merendree, 1756-Drongen, 1818). Geillustreerd.

266. In Memoriam, in Kultureel Jaarboek voor de Provincie OostVlaanderen, 42, (1988), p. 187-191.

Korte biografische nota's van de in 1988 overleden Gentse journalist Gontran van Severen (Gent, 1904), musikoloog Ignace de Sutter (Gent, 1911) en dichter Hans Melen (Deinze, 1914). Met foto's.

267. In Memoriam Gaston Hebbelynck (1912-1989), in Ghendtsche Tydin. ghen, 19, (1990), nr. 1, p. 2-4. 
Hebbelynck was stichter-voorzitter van de Heemkundige en Historische Kring Gent. Met foto.

268. KLUYSKENS P., Joseph-Pierre Braemt, in Ghendtsche Tydinghen, 18 , (1989), nr. 6, p. 305-309.

Braemt (Gent, 1796-Laken, 1864) was een vermaard graveur. Met foto.

269. LEKENS L., Jozef Cantré 1890-1957, in G.O.V.-Heraut, 25, (1990), nr. 5,8 blz.

Biografische schets van deze Gentse houtsnijder en beeldhouwer. Geillustreerd.

270. LEKENS L., Karel Miry 1823-1889, in G.O.V.-Heraut, 25, (1990), nr. 3, 4 blz. Geillustreerd.

271. LEVIS E., In memoriam Gill. van Geert, in Ghendtsche Tydinghen, 19, (1990), nr. 3, p. 163-167.

In memoriam over de volkskenner en kunstenaar Gilbert Van Geert (1930-1990). Geillustreerd.

272. Lucien de Coninck (1909-1988). Bioloog-humanist-'t Zaller, ('t Zal Wel Gaan, nr. 2), Gent, 1990, 67 blz.

Diverse bijdragen over leven en werk van de Gentse prof. in de wetenschappen (biologie) De Coninck.

273. Nationaal biografisch woordenboek. 13, (Koninklijke Academiën van België), Brussel, 1990, VII + 904 + VIII blz. en kol.

Betreffende Gent werden opgenomen : de socialistische leider en politicus Edward Anseele, 1856-1938 (37-45); de handelaar en politicus Joseph Boëyé, 1766-1835 (104-106); de letterkundige Jan Bouchery, 1846-1911 (109-114); de liberale burgemeester Emile Braun, 1849-1928 (119-124); de toneelakteur Staf Bruggen, 1893-1964 (124-140); de hoogleraar en letterkundige Amaat Burssens, 1897-1983 (148-154); bisschop Charles Calewaert, 1893-1963 (159-163); bisschop Honoré Coppieters, 1874-1947 (170-175); de geneesheer en aktivist Gustave Doussy, 1881-1948 (251-256); de hoogleraar en filoloog Robert Foncke, 1889-1975 (276-281); de jurist en pensionaris Simon van Formelis, vóór 1374-1447 (286-292); de ambtenaar en taalkundige Jan Grauls, 1887-1960 (337-344); de makelaar Conte Gualterotti, ca. 1270-1339 (344-346); de burgemeester Jean Baptiste d'Hane de Steenhuyse, 1757-1826 (362-365); de komponist Karel Hanssens junior, 1802-1871 (366-371); de komponist Karel Hanssens senior, 1777-1852 (371-373); de geestelijke schrijver Roeland Heelaudt, ? -na 1649 (378-380); de filoloog en dichter Daniël Heinsius, 1580-1655 (383-389); de architekt Geo Henderick, 1879-1957 (396-401); de politicus Eugène Hoobrouck de Mooreghem, 1756-1843 (406-410); bisschop Henri Lambrecht, 1848-1889 (459-465); de advokaat en uitgever Constant Leirens, 
1813-1886 (489-495); de jurist en hoogleraar Jean Limpens, 1910-1979 (498-504); de patriciër en ambtenaar Lauwereins de Maech, ca. 1410-1468 (515-519); de beeldhouwer en kunstschilder Lodewijk Mast, 1857-1901 (543-547); de germanist en hoogleraar George Meir, 1900-1944 (550-554); de letterkundige Philippus de Pillecyn, 1891-1962 (642-648); de komponist Adolphe Samuel, 1824-1898 (730-734); de kunstschilder Gust. de Smet, 1877-1943 (750-759); de onderwijzer en stichter van het Schoolmuseum Leo Thiery, 1877-1950 (775-779); de onderwijzer en vredesopvoeder Geo Verbrugge, 1896-1977 (801-803); de architekt en politicus Arthur Verhaegen, 1847-1917 (816-822); de advokaat en politicus Julius de Vigne, 1844-1908 (827-835); de taalkundige en hoogleraar Willem de Vreese, 1869-1938 (850-860); de taalkundige, hoogleraar en politicus Auguste Wagener, 1829-1896 (861-870); de militant en dissidente socialist Paul de Witte, 1848-1929 (880-885); de kunstschilder Rodolphe Wytsman, 1860-1927 (895-900); de ambtenaar en politicus Daneel van Zeveren, laatste kwart 14de eeuw-1432 (901-904).

274. Oscar Colbrandt-Albert Servaes 1900-1930, Brussel, 1989, $119 \mathrm{blz}$. Kataloog van een konfrontatietentoonstelling tussen twee Gentse religieuze kunstenaars : Colbrandt (1879-1959) en Servaes (1883-1966). Met woord vooraf door de voorzitter van het Gemeentekrediet F. NARMON, ten geleide door de burgemeester van Hasselt L. ROPPE en teksten over de kunstenaars en hun werk door P. HUYS, L.M.A. SCHOONBAERT, R. CLEMENT en J. D'HAESE. Geilllustreerd. Zie ook Oscar Colbrandt 1879-1959, (Museum dr. Guislain), Gent, $1989,63 \mathrm{blz}$.

275. POELMAN R., Jozefus Judocus de Werweirne, soldaat van Napoleon, in Heemkundig Nieuws, 18, (1990), nr. 2, p. 11-14.

De Weweirne (Gent, 1787-1866) was fuselier van het keizerlijk leger in Spanje en Oostenrijk. Met foto van zijn grafmonument op het Campo Santo.

276. POELMAN R., Kunstschilder Lieven van den Dorpe (1904-1987), in Heemkundig Nieures, 18, (1990), nr. 5, p. 3-10.

Van den Dorpe (Sint-Amandsberg, 1904-Lovendegem, 1987) schilderde monumentale doeken met religieuze inslag. Geilllustreerd.

277. Retrospectieve tentoonstelling Maurice Sys 1880-1972, (Museum van Deinze en de Leiestreek), Deinze, 1989, 55 blz.

Sys (Gent, 1880-1972) schilderde portretten, landschappen en stadsgezichten, maar vooral zee- en havengezichten. De kataloog bevat een overzicht van leven en werk door G. SIJS, een bloemlezing uit gepubliceerde kunstkritieken en een lijst van de tentoon gestelde werken. Met voorwoord door schepen J. DE RUYCK en illustraties. 
278. TAVERNIER D. en R. VAN NIEUWENBORGH, Auguste van Lokeren (1799-1872). Portret van een oudheidkundig pionier, in Stadsarcheologie, 14, (1990), nr. 2, p. 3-31. Geïllustreerd.

279. VAN AKEN P., Jos Murez, in Oostvlaamse Literaire Monografieën, IX, (1989) p. 97-128.

Murez (Bevere, 1927-) is schrijver van dichtbundels, essays, monografieën en andere prozawerken. Hij was medewerker aan de krant Vooruit en De Streekkrant. Met illustraties.

280. VANDERMEERSCH P., Een uitzonderlijk egodocument: Maarten Snouckaert (1514-1569?) over zijn jeugd, zijn opvoeding, zijn studies, in Liber Amicorum Acbiel De Vos, Evergem, 1989, p. 219-228.

Snouckaert genoot een door het humanisme geïnspireerde opleiding te Brugge, bij de broeders van het Gemene Leven te Gent en aan de universiteit te Leuven.

281. VAN DE WOESTIJNE P., Het memorieboek van de Eeklonaar Pieter Dierkens (1547-1628), in Liber Amicorum Acbiel De Vos, Evergem, 1989, p. 229-236.

Levensschets van Pieter Dierkens, die vóór 1584 uit Eeklo emigreerde naar Gent, aan de hand van een "memorieboek".

282. VAN ELSLANDE R., De Beverenaar Joos Vyt, diplomaat van Filips de Goede, in Het Land van Beveren, XXXI, (1989), nr. 3, p. 98-112. Levensschets van Vyt (Beveren, ?-Gent, 1439), de schenker van het Lam Godsretabel. Met illustratie.

283. VANLANDSCHOOT R., René de Clercq (1877-1932). Aantekeningen bij de bekroonde studie van K. Hulpiau, in Wetenscbappelijke Tijdingen, XLVIII, (1989), nr. 2, p. 65-73.

284. VAN RYSSEL D., Julien Vangansbeke, in Oostvlaamse Literaire Monografieën, IX, (1989), p. 1-32.

Vangansbeke (Drongen, 1936-) publiceert vooral poëzie, kortverhalen en beschouwend proza. Geîllustreerd. 